\title{
The challenge of Inotuzumab ozogamicin treatment as "bridge to transplant" in relapsed/refractory B cell-acute lymphoblastic leukemia
}

Radici Vera ${ }^{1}$, De Marchi Roberta ${ }^{1}$, Sperotto Alessandra ${ }^{1}$, Cerno Michela ${ }^{1}$, Geromin Antonella ${ }^{1}$, Battista Marta Lisa ${ }^{1}$, Candoni Anna $^{1}$, Fili Carla $^{1}$, Zannier Maria Elena ${ }^{1}$, Lazzarotto Davide ${ }^{1}$, Simeone Erica ${ }^{1}$, Dubbini Maria Vittoria ${ }^{1}$, Rabassi Nicholas ${ }^{1}$, Facchin Gabriele ${ }^{1}$, Fanin Renato $^{1,2}$ and Patriarca Francesca ${ }^{1,2}$

${ }^{1}$ Clinical Hematology and Bone Marrow Transplant Centre, S. Maria della Misericordia University Hospital, Italy

${ }^{2} \mathrm{DAME}$, University of Udine, Udine, Italy

\begin{abstract}
Background: Inotuzumab ozogamicin, a humanized anti-CD22 monoclonal antibody conjugated to the cytotoxic antibiotic agent calicheamicin, has demonstrated efficacy in the phase 3 INO-VATE study in adults with relapsed or refractory B-acute lymphoblastic leukemia (ALL). Findings from the study showed severe adverse events associated with Inotuzumab, with veno-occlusive disease (VOD) reported as a major non-hematologic toxicity.

Cases presentation: We report the outcome of 4 patients with diagnosis of B-ALL, receiving Inotuzumab as salvage treatment for refractory disease and "bridge to" hematopoietic stem cell transplantation. They received 2 or 3 cycles of Inotuzumab, followed by reduced intensity conditioning regimens and reinfusion of peripheral blood stem cells from related (3) or unrelated donors (1). All patients had several risk factors for developing VOD. Three out of 4 patients developed VOD and 2 of them showed a fatal course, despite of early start of defibrotide treatment.

Conclusions: On the basis of our clinical experience and the previously reported data, we have proposed a strategy in order to minimize VOD risk providing accurate selection of transplant candidates, choice of conditioning regimens without full dose of alkylating agents, monitoring of liver stiffness and reserving defibrotide prophylaxis in patients with persisting risk factors for VOD.
\end{abstract}

\begin{abstract}
Abbreviations: INO: Inotuzumab; ALL: acute lymphoblastic leukemia; SOS: sinusoidal obstruction syndrome; VOD: venoocclusive disease; HSCT: hematopoietic stem cell transplantation; MOF: multi organ failure; TBI: total body irradiation; CAR-T: chimeric antigen receptor T-cell; MRD: minimal residual disease; HLA: human leukocyte antigen; EBMT: European Group for Blood and Marrow Transplantation.
\end{abstract}

\section{Introduction}

Despite improved outcome over the past 30 years, the prognosis for adults with relapsed or refractory acute lymphoblastic leukemia (ALL) remains poor. Attaining complete remission of ALL before hematopoietic stem cell transplantation (HSCT) strictly correlates with the post-transplant outcome. Salvage therapy had conventionally consisted of standard multiagent chemotherapy. However, 3 groundbreaking immunotherapies have been recently approved in this setting: inotuzumab, blinatumumab and CAR-T. Inotuzumab (InO) is a humanized IgG4 monoclonal antibody that binds with high affinity to CD22, a specific B cell-surface antigen present in over $90 \%$ of patients with ALL $[1,2]$. The safety and efficacy of InO were analized in a randomized, open-label, clinical trial called INO-VATE [3]. InO monotherapy was evaluated against intensive chemotherapy in patients in first or second relapse, or in those who were refractory to previous treatments. InO showed significantly higher rates of complete remission and minimal residual disease (MRD) negativity in comparison with chemotherapy. Moreover, InO significantly improved median progression free and overall survival, reducing by $25 \%$ the risk of death. However, several clinically relevant adverse events associated with $\mathrm{InO}$ were reported. As with other antibodies conjugated to calicheamicin, a high rate of hepatotoxicity $(50.6 \%$ vs $36.4 \%$ in the chemotherapy arm), was a concern with $\mathrm{InO}[3,4]$.

Herein we report a cases series of 4 patients with relapse/refractory ALL who were treated with InO and underwent HSCT, with the aim of describing VOD risk factors and management of hepatotoxicity linked to Inotuzumab.

\section{Cases presentation}

Four patients aged between 22 and 70 years with B-ALL (3 Philadelphia negative and 1 Philadelphia positive ALL) had relapsed after HSCT (allogeneic SCT in 2 cases and autologous SCT in 1 case) or chemotherapy plus thyrosinkinase inhibitors (1 patient) (Table 1).

${ }^{\star}$ Correspondence to: Francesca Patriarca, MD, Clinica Ematologica e Centro Trapianti e Terapie Cellulari "Carlo Melzi”, Azienda Sanitaria-Universitaria Integrata, Piazzale S.Maria della Misericordia 10, 33100 Udine, Italy, Tel 0039 432 559662; Fax: 0039432 559661; E-mail: francesca.patriarca@asuiud.sanita.fvg.it

Key words: inotuzumab, veno occlusive disease, heamatopoietic stem cell transplantation, defibrotide, CD22 monoclonal antibody

Received: October 31, 2019; Accepted: November 07, 2019; Published: November 11, 2019 
Table 1. Summary of characteristics of patients and transplants

\begin{tabular}{|c|c|c|c|c|}
\hline & PATIENT 1 & PATIENT 2 & PATIENT 3 & PATIENT 4 \\
\hline AGE AT HSCT & 22 years & 70 years & 39 years & 60 years \\
\hline DIAGNOSIS & ALL Pro-B Ph- & ALL Common Ph- & ALL Pre-B Ph- & ALL B Ph+ (p190) \\
\hline PREVIOUS THERAPY & $\begin{array}{l}\text { - Protocol GIMEMA LAL } \\
\text { - } \text { CNS prophylaxis } \\
\text { - } 2 \text { cycles of Blinatumumab } \\
\text { - First HLA-ID (brother) HSCT } \\
\text { - Clofarabine + CP }\end{array}$ & $\begin{array}{l}\text { - } \text { Protocol GIMEMA LAL } \\
\text { - CNS prophylaxis } \\
\text { - ASCT (Melphalan) } \\
\text { - } 3 \text { maintenance cycles }\end{array}$ & $\begin{array}{l}\text { - } \text { Protocol GIMEMA LAL } \\
\text { - } \text { CNS prophylaxis } \\
\text { - } 3 \text { cycles of reinduction } \\
\text { - } \text { First HAPLO (brother) HSCT } \\
\text { - MEC }\end{array}$ & $\begin{array}{l}\text { - } \text { Dasatinib } \\
\text { - } 3 \text { cycles HyperCVAD } \\
\text { - } \text { CNS prophylaxis } \\
\text { - } \text { Ponatinib } \\
\text { - High Dose MTX }\end{array}$ \\
\hline N. OF CYCLES OF INO & 2 & 2 & 3 & 2 \\
\hline INTERVAL INO-HSCT & 56 days & 44 days & 34 days & 72 days \\
\hline CONDITIONING REGIMEN & Busulfan, Fludarabine & Treosulfan, Fludarabine & TBI 2 Gy, CP, Fludarabine & Treosulfan, Fludarabine \\
\hline HCT-CI & 2 & 2 & 2 & 5 \\
\hline DONOR & HAPLO (mother) & HLA-ID (brother) & HAPLO (brother) & MUD 9/12 \\
\hline GVHD PROPHYLAXIS & CP, FK, MMF & ATG, Cya, MTX & CP, FK, MMF & ATG, FK, MTX \\
\hline VOD RISK FACTORS & $\begin{array}{l}\text { Advanced disease } \\
\text { Iron overload } \\
\text { No T-cell depletion } \\
\text { Second transplant } \\
\text { Previous Hepatic GvHD } \\
\text { Elevated pre-HSCT AST/ALT } \\
\text { HLA mismatch } \\
\text { TBI }\end{array}$ & $\begin{array}{l}\text { Advanced disease } \\
\text { Iron overload }\end{array}$ & $\begin{array}{l}\text { Advanced disease Iron overload } \\
\text { No T-cell depletion } \\
\text { Second transplant } \\
\text { TBI }\end{array}$ & $\begin{array}{l}\text { Advanced disease } \\
\text { Iron overload }\end{array}$ \\
\hline $\begin{array}{l}\text { DIAGNOSIS OF VOD } \\
\text { (SEATTLE-BALTIMORA } \\
\text { CRITERIA) }\end{array}$ & YES (+3) & YES (+15) & $\begin{array}{l}\text { NO } \\
\text { cytokine release syndrome } \\
\text { (no VOD criteria) }\end{array}$ & YES (+4) \\
\hline TREATMENT & DEFIBROTIDE & DEFIBROTIDE & NONE & DEFIBROTIDE \\
\hline OUTCOME & $\begin{array}{l}\text { DEAD } \\
(+14 \text { days } \\
\text { from } \mathrm{HSCT})\end{array}$ & $\begin{array}{l}\text { DEAD } \\
(+22 \text { days } \\
\text { from } \text { HSCT })\end{array}$ & $\begin{array}{l}\text { ALIVE } \\
(+22 \text { months from HSCT })\end{array}$ & $\begin{array}{l}\text { ALIVE } \\
(+100 \text { days } \\
\text { from HSCT })\end{array}$ \\
\hline
\end{tabular}

HSCT Hematopoietic stem cell transplantation; ALL Acute lymphoblastic leukemia; Ph Philadelphia; CNS Central nervous system; HLA-ID HLA-Identical; CP Cyclophosphamide; ASCT Autologous stem cell transplant; MTX Methotrexate; Ino Inotuzumab; HCT-CI The Hematopoietic Cell Transplantation specific Comorbidity Index; TBI Total Body Irradiation; HAPLO haploidentical; MUD Matched Unrelated Donor; GVHD Graft versus Host Disease; VOD Veno-occlusive disease; ATG Anti-thymocyte globulin; FK Tacrolimus; CyA cyclosporine; MMF mycophenolate mofetil.

Three out of 4 patients had previously failed one line of salvage conventional chemotherapy before receiving $\mathrm{InO}$, while 1 patient was submitted to InO immediatly after relapse. They received 2 to 3 cycles of InO cycles, followed by different reduced intensity conditioning regimens and HSCT. Median time between the last InO cycle and reinfusion of stem cells was 51 days (range 34-71 days).

Reduced intensity conditioning regimens included busulfan or treosulfan in 3 cases and 2 Gy of total body irradiation (TBI) in 1 patient. Three patients received stem cells from a related donor: 2 haploidentical donors and 1 HLA-identical brother. One patient had a mismatched unrelated donor. All patients received peripheral blood stem cells. Table 1 summarized VOD risk factors [5] of each patient.

All patients had advanced disease, iron overload and 3 out of 4 patients had a prior HSCT [6].

Patient n.3 didn't develop VOD or any sign of hepatoxicity. The only complication was a transient cytokine release syndrome after stem cell reinfusion. She is still alive and in complete remission 24 months after HSCT. She is the only patient who had received a conditioning regimen without busulfan or treosulfan.

Three patients developed VOD and they were all promptly treated with defibrotide since VOD diagnosis. Patient n.4 had a mild VOD recovering without sequelae. The other 2 patients developed VOD with fatal course.

Patient n.2 showed acute respiratory distress syndrome associated with Influenza pneumonia requiring mechanic ventilation in the Intensive Care Unit. After bilirubin level had raised, a treatment with defibrotide at a dose of $25 \mathrm{mg} / \mathrm{kg} /$ day was immediately initiated and continued for 6 days, until patient death because of multi-organ-failure (MOF).
Figure 1 describes the clinical course of patient n.1. At the time of transplant she had several risk factor for developing VOD, including advanced disease, prior HSCT complicated with hepatic Graft Versus Host Disease, elevated hepatic blood tests within 2 times the normal values (alkaline phosphatase, gamma glutamyl transferase, total bilirubin without transaminase elevations), HLA mismatch and previous TBI. The day after transplant the patient developed weight gain (>2\% basal weight) without bilirubin level raise. Since it could not be ruled out an early onset of VOD, on day +1 defibrotide was promptly started in association with diuretic therapy, even though diagnostic VOD criteria were not all satisfied. On Day +5 the patient was categorized as very severe VOD stage, according to EBMT severity criteria [7], because of doubling of bilirubin serum level in 48 hours and weight gain $>5 \%$. The next day ascites and pleural and pericardial effusions were documented and her clinical condition got worse. She needed oxigen therapy and supportive therapy. Since day +8 she had a rapid progression of VOD to MOF leanding to death on day +14 after transplant.

\section{Discussion}

InO, like other novel immune-targeted therapies, is an attractive treatment in order to achieve remission in patients with relapsed/ refractory B-ALL and to allow a subsequent HSCT and it is relatively well-tolerated [8]. However, similarly to gemtuzumab ozogamicin, an anti CD-33 antibody linked to calicheamicin, InO is associated to an increase incidence of VOD $[9,10]$. VOD is a potentially fatal liverrelated complication of HSCT [4], that can progress quickly from a mild to a severe form; the latter is reported to cause death in more than $80 \%$ of cases [11]. 

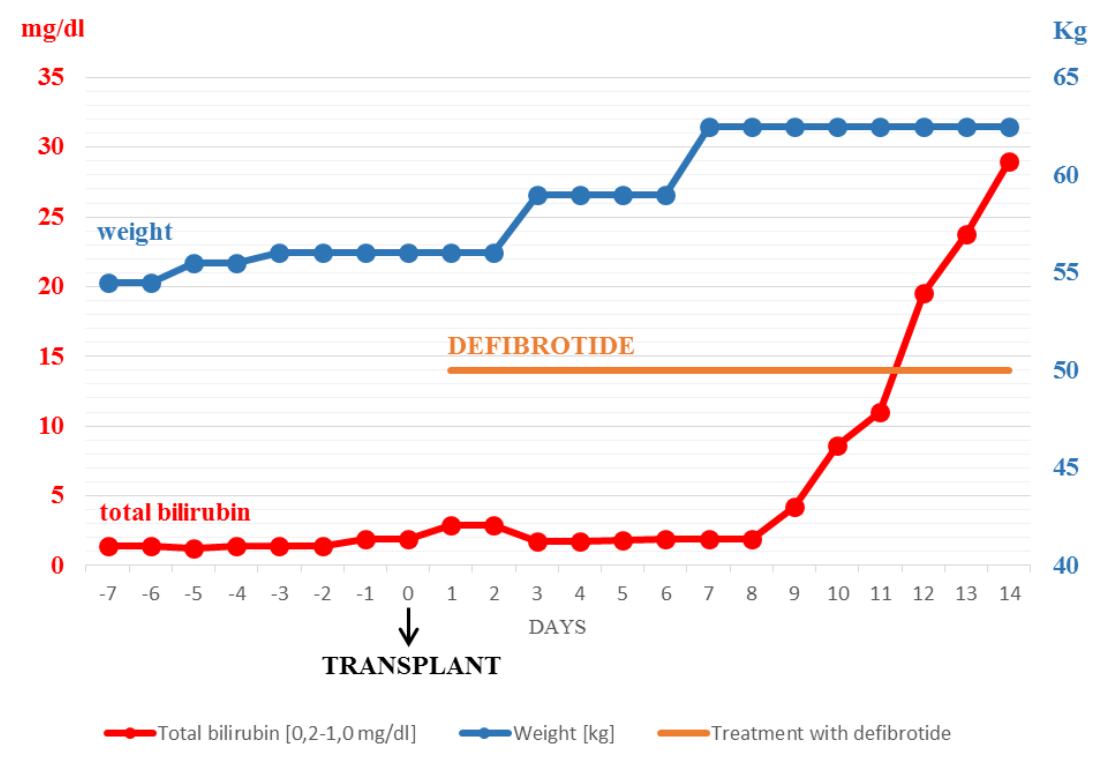

Figure 1. Course of some clinical signs and laboratory exams during VOD in patient n.1

In the INO-VATE study, the incidence of any grade and grade $\geq$ 3 VOD was significantly higher in the InO group compared with the standard-therapy group $(13 \%$ and $11 \%$ in comparison with $<1 \%$ and $<1 \%$, respectively) [9]. Among the 23 VOD events reported in the trial, 18 (78\%) developed after HSCT and were fatal in 5 cases. The incidence of VOD was higher in the pediatric cohort with an overall rate of $52 \%$ and all the complications were observed after HSCT [12].

Our clinical experience confirms the high incidence of VOD in InO-treated patients. In fact, 3 of 4 patients developed VOD, with a fatal course in 2 of them, despite early treatment with defibrotide. However, all our patients had several risk factors for developing VOD, linked to the advanced disease and the heavy pre-treatment including HSCT, and the conditioning regimen based on alkylating agents. The youngest patient with the rapidly progressive course of VOD had preexisting alterations of the liver serum tests, suggesting an initial liver damage.

On the basis of this experience, we have revised our strategy in order to minimize the VOD risk. First, we intend to select the candidates of HSCT among InO-treated patients, excluding those with a prior mieloablative HSCT or abnormalities of hepatic laboratory tests. Secondly, we would avoid conditioning regimens with full dose busulfan and we would prefer reduced intensity or nonmyeloablative preparative regimens, that can be offer only to patients with a deep complete remission after InO. Moreover, the management of these patients should provide monitoring of liver stiffness with ultrasound elastography techniques (Acoustic Radiation Force Impulse or Fibroscan) [13-15,17] after HSCT, in order to allow early diagnosis before the clinical picture of VOD will be overt and the tissue damage will be irreversible. With the aim of defining the role of liver stiffness measurement in the early diagnosis of VOD, a prospective multicenter study is ongoing at the centers of the Gruppo Italiano Trapianto Midollo Osseo (GITMO) [16], evaluating patients receiving autologous and allogeneic HSCT. Lastly, prophylaxis with defibrotide, which was reported to significantly reduce VOD incidence in retrospective studies in both adults and children [8,18-22], and a randomized trial in children [23] could be reserved for patients with persisting risk factors for VOD and strict indication for HSCT.

\section{Acknowledgements}

None

\section{Author's contributions}

The authors declare that they have no competing interests. The original manuscript was written by VR and revised by FP. All authors contributed to the clinical data and they read and approved the final manuscript.

\section{References}

1. Yurkiewicz IR, Muffly L, Liedtke M (2018) Inotuzumab ozogamicin: a CD22 mAbdrug conjugate for adult relapsed or refractory B-cell precursor acute lymphoblastic leukemia. Drug Des Devel Ther 12: 2293-2300. [Crossref]

2. DeAngelo DJ, Stock W, Stein AS, Shustov A, Liedtke M, et al. (2017) Inotuzumab ozogamicin in adults with relapsed or refractory CD22-positive acute lymphoblastic leukemia: a phase 1/2 study. Blood $\operatorname{Adv} 1$ : 1167-1180. [Crossref]

3. Kantarjian HM, DeAngelo DJ, Stelljes M, Liedtke M, Stock W, et al. (2019) Inotuzumab ozogamicin versus standard of care in relapsed or refractory acute lymphoblastic leukemia: Final report and long-term survival follow-up from the randomized, phase 3 INO-VATE study. Cancer 125: 2474-2487. [Crossref]

4. Kebriaei P, Cutler C, de Lima M (2018) Management of important adverse events associated with inotuzumab ozogamicin: expert panel review. Bone Marrow Transplant 53: 449-456.

5. Dalle JH, Giralt SA (2016) Hepatic veno-occlusive disease after hematopoietic stem cell transplantation: risk factors and stratification, prophylaxis, and treatment. Biol Blood Marrow Transplant 22: 400-409.

6. Mohty M, Malard F, Abecassis M (2015) Sinusoidal obstruction syndrome/venoocclusive disease: current situation and perspectives-a position statement from the European Society for Blood and Marrow Transplantation (EBMT). Bone Marrow Transplant 50: 781-789.

7. Mohty M, Malard F, Abecassis M, Aerts E, Alaskar AS, et al. (2016) Revised diagnosis and severity criteria for sinusoidal obstruction syndrome/veno-occlusive disease in adult patients: a new classification from the European Society for Blood and Marrow Transplantation. Bone Marrow Transplant 51: 906-912. [Crossref]

8. Bhojwani D, Sposto R, Shah NN (2019) Inotuzumab ozogamicin in pediatric patients with relapsed/refractory acute lymphoblastic leukemia [published correction appears in Leukemia. Leukemia 33: 884-892.

9. Kantarjian HM, DeAngelo DJ, Advani AS, Stelljes M, Kebriaei P, et al. (2017) Hepatic adverse event profile of inotuzumab ozogamicin in adult patients with relapsed or refractory acute lymphoblastic leukaemia: results from the open-label, randomised, phase 3 INO-VATE study. Lancet Haematol 4: e387-e398. 
10. Wadleigh M, Richardson PG, Zahrieh D, Lee SJ, Cutler C, et al. (2003) Prior gemtuzumab ozogamicin exposure significantly increases the risk of veno-occlusive disease in patients who undergo myeloablative allogeneic stem cell transplantation. Blood 102: 1578-1582.

11. Coppell JA, Richardson PG, Soiffer R, Martin PL, Kernan NA, et al. (2010) Hepatic veno-occlusive disease following stem cell transplantation: incidence, clinical course, and outcome. Biol Blood Marrow Transplant 16: 157-168.

12. Bhojwani D, Sposto R, Shah NN (2019) Inotuzumab ozogamicin in pediatric patients with relapsed/refractory acute lymphoblastic leukemia [published correction appears in Leukemia. Leukemia 33: 884-892.

13. Richardson PG, Ho VT, Cutler C, Glotzbecker B, Antin JH, et al. (2013) Hepatic VenoOcclusive Disease after Hematopoietic Stem Cell Transplantation: Novel Insights to Pathogenesis, Current Status of Treatment, and Future Directions. Biol Blood Marrow Transplant 19: S88-S90.

14. Richardson PG, Riches ML, Kernan NA (2016) Phase 3 trial of defibrotide for the treatment of severe veno-occlusive disease and multi-organ failure. Blood 127: 1656-1665.

15. Richardson PG, Smith AR, Triplett BM (2017) Earlier defibrotide initiation postdiagnosis of veno-occlusive disease/sinusoidal obstruction syndrome improves Day +100 survival following haematopoietic stem cell transplantation. Br J Haematol 178: 112-118.

16. Colecchia A, Ravaioli F, Sessa M, Alemanni VL, Dajti E, et al. (2019) Liver Stiffness Measurement Allows Early Diagnosis of Veno-Occlusive Disease/Sinusoida Obstruction Syndrome in Adult Patients Who Undergo Hematopoietic Stem Cel Transplantation: Results from a Monocentric Prospective Study. Biol Blood Marrow Transplant 25: 995-1003.
17. Colecchia A, Marasco G, Ravaioli F, Kleinschmidt K, Masetti R, et al. (2016) Usefulness of liver stiffness measurement in predicting hepatic veno-occlusive disease development in patients who undergo HSCT. Bone Marrow Transplant 52: 1-4.

18. Cheuk DKL, Chiang AKS, Ha SY, Chan GCF (2015) Interventions for prophylaxis of hepatic veno-occlusive disease in people undergoing haematopoietic stem cell transplantation. Cochrane Database Syst Rev 27: CD009311.

19. Chalandon Y, Roosnek E, Mermillod B (2004) Prevention of veno-occlusive disease with defibrotide after allogeneic stem cell transplantation. Biol Blood Marrow Transplant 10: 347-354.

20. Park M, Park HJ, Eom HS, Kwon YJ, Park JA, et al. (2013) Safety and effects of prophylactic defibrotide for sinusoidal obstruction syndrome in hematopoietic stem cell transplantation. Ann Transplant 18: 36-42.

21. Cappelli B, Chiesa R, Evangelio C, Biffi A (2009) Absence of VOD in paediatric thalassaemic HSCT recipients using defibrotide prophylaxis and intravenous Busulphan. Br J Haematol 147: 554.

22. Dignan F, Gujral D, Ethell M, Evans S, Treleaven J, et al. (2007) Prophylactic defibrotide in allogeneic stem cell transplantation: minimal morbidity and zero mortality from veno-occlusive disease. Bone Marrow Transplant 40: 79.

23. Corbagioglu S, Cesaro S, Faraci M, Valteau-Couanet D, Gruhn B, et al. (2012) Defibrotide for prophylaxis of hepatic veno-occlusive disease in paediatric hemopoietic stem cell transplantation: an open-label, phase 3, randomised controlled trial. Lancet 379: 1301-1309.

Copyright: (C2019 Vera R. This is an open-access article distributed under the terms of the Creative Commons Attribution License, which permits unrestricted use, distribution, and reproduction in any medium, provided the original author and source are credited. 